\title{
PROYECTO VERANES. ARQUEOLOGÍA E HISTORIA EN TORNO A LA VÍA DE LA PLATA EN EL CONCEJO DE GIJÓN (ASTURIAS)
}

\author{
CARMEN FERNÁNDEZ OCHOA \\ FERNANDO GIL SENDINO \\ YOLANDA PEÑa CERVANTES \\ GONZALO ÁlVAREZ TOLEDO \\ Universidad Autónoma de Madrid
}

JOSE ANTONIO SUÁREZ

PELAYO GONZALEZ-PUMARIEGA

RAMON J. ARGUELLES

ANGEL R. VIDAL

E.U.I.T. Minera y Topográfica de Mieres

\section{Resumen}

Se presentan en estas páginas los objetivos, los planteamientos metodológicos y los primeros resultados del "Proyecto Veranes", yacimiento tardorromano y medieval situado en las proximidades de la ciudad de Gijón. Dicho proyecto, financiado mayoritariamente por el ilmo. Ayuntamiento de Gijon, es el fruto de un esfuerzo coordinado entre diversas instituciones publicas.

\section{Summary}

In this paper we present the ains, the methodological proposals and the first results of Veranes Project. a Late-Roman and Medieval archaeological site near the city of Gijon. The main part of this project is financed by Gijon City Council and aiso constitutes the effort among different public institutions.

\section{INTRODUCCIÓN}

En el año 1997 el Ilmo. Ayuntamiento de Gijón firmó sendos convenios uno con la Universidad de Oviedo y otro con la Universidad Autónoma de Madrid para llevar adelante un nuevo proyecto de investigación arqueológica en el Concejo de Gijón. El proyecto ha contado también con el apoyo y la colaboración de la Consejería de Educación 
y Cultura del Principado de Asturias y se ha puesto en marcha bajo el título de "Arqueología e Historia en torno a la vía de la Plata en el Concejo de Gijón"

Dicho proyecto supone la continuidad de la actividad arqueológica patrocinada por el Ayuntamiento de Gijon y desarrollada tanto en el centro de la ciudad como en el Concejo a lo largo de la última década con el fin de descubrir y aclarar los orígenes históricos de los territorios gijoneses (FERNANDEZ OCHOA, 1996) ${ }^{1}$.Como objetivos prioritarios de esta nueva etapa de las investigaciones arqueológicas en Gijón, cabe señalar aquellos que se refieren tanto a la investigación histórico-arqueológica en un sentido estricto cuanto a los que tratan de preservar el importante patrimonio del Concejo y, siempre que ello sea posible, mostrarlo a los ciudadanos como testimonio de la propia identidad cultural fraguada a lo largo de los siglos.

El nuevo proyecto se articula en relación con un espacio geográfico concreto que es el extremo suroccidental del Concejo correspondiente al trazado de la antigua vía que procedente de León y Astorga, se adentraba en la región central asturiana llegando por Lugo de Llanera hasta Gijón (FERNÁNDEZ OCHOA, 1982 y 1995) El tramo entre Llanera y Gijón aunque no aparece citado expresamente por las fuentes literarias es la prolongación de la Via de la Plata procedente de Astorga y presenta en la actualidad un conjunto de restos y yacimientos cuyo estudio nos hemos propuesto realizar de forma sistemática comprendiendo un amplio margen cronológico desde el mundo prerromano hasta la Edad Media.

Tan amplio espectro temporal necesariamente requiere la colaboración de distintas instituciones, diversos equipos de investigadores así como la participación de especialistas en materias complementarias de la Arqueologia de campo. Por estas razones, y como más adelante veremos, en el nuevo proyecto se han integrado distintas instituciones y se han repartido las acciones y tareas a realizar. La propuesta inicial contemplaba la práctica de excavaciones en el castro de Serín, en el yacimiento tardorromano y medieval Veranes y en la fortaleza medieval de Peñaferruz conocida como Picu Alba ${ }^{2}$ En la actualidad se han iniciado las investigaciones exclusivamente en Veranes y en Peñaferruz

\section{FUENTES HISTÓRICAS Y REFERENCIAS HISTORIOGRÁFICAS}

Los restos arqueológicos de Veranes, conocidos desde antiguo como "Torrexón de San Pedro", comprenden aproximadamente $1 \mathrm{Ha}$. de extensión y se sitúan en el lugar conocido como "Venta de Veranes" de la parroquia de Cenero, a $8 \mathrm{Km}$. de la capital gijonesa junto a la carretera antigua de Gijón a Oviedo (N-630, Km.460-461) (Fig. 1). El yacimiento

\footnotetext{
${ }^{1}$ Agradecemos a Paloma Garcia Diaz su colaboración en la génesis del Proyecto Veranes. Igualmente expresamos nuestra gratitud a Isidoro Cortina que siempre nos proporciona interesantes informaciones sobre el Patrimonio Histórico del Concejo de Gijón

${ }^{2}$ Las excavaciones en la fortaleza de Pehaferruz están siendo dirtgidas por el prof. Avelino Gutiérrez de la Universidad de Oviedo y comprenden, además, una prospección de los lugares de la ruta que presentan restos medievales.
} 


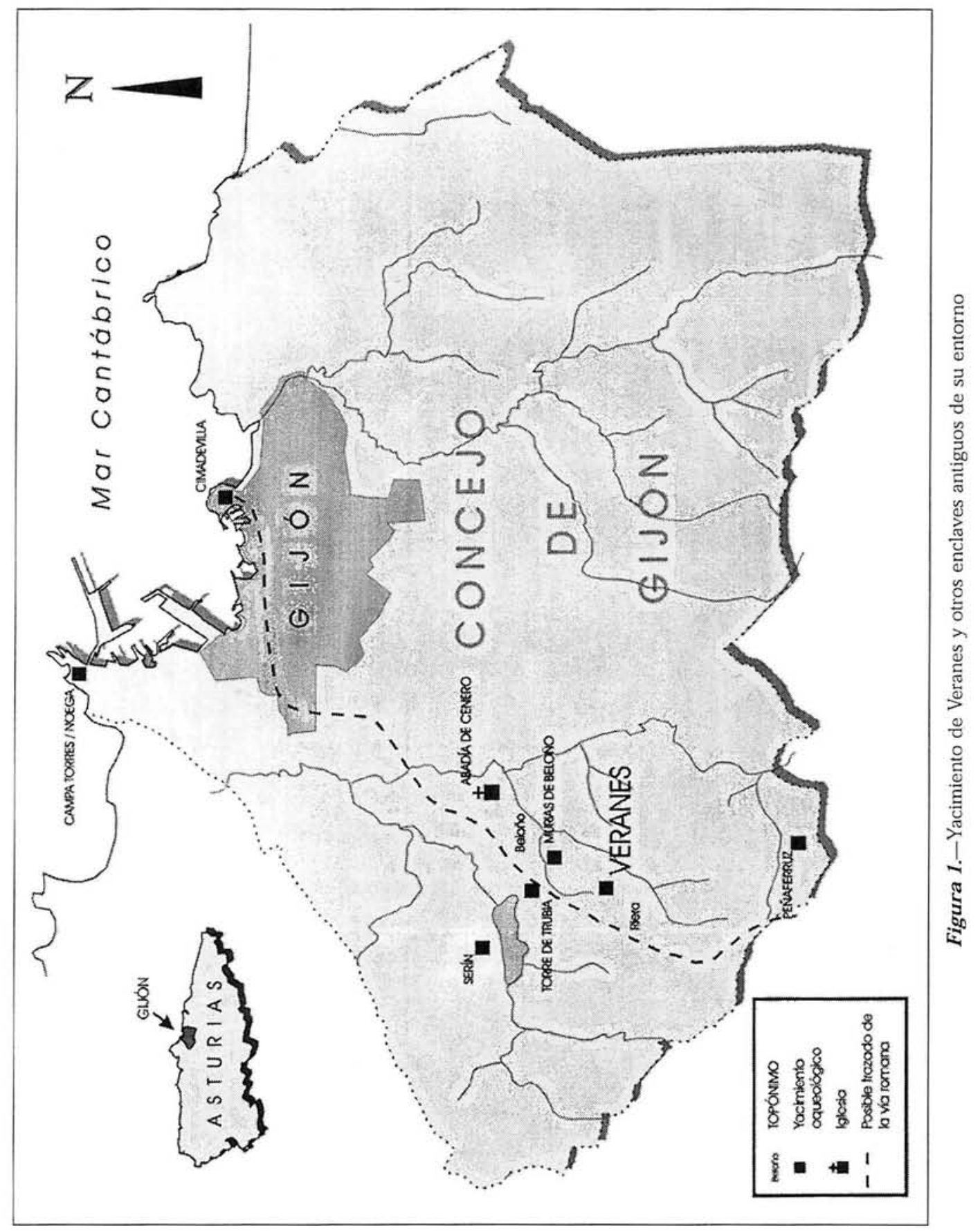


ocupa una vertiente a media ladera, a unos $150 \mathrm{~m}$. sobre el nivel del mar. El aspecto que presentan las ruinas emergentes, con muros de mampostería de mas de $4 \mathrm{~m}$. de altura, restos de salas de grandes dimensiones, estancias calefactadas y fragmentos de pinturas parietales, asi como una extensa necrópolis medieval, confieren a este yacimiento un enorme valor monumental que ha atraído desde hace casi un siglo la atención de eruditos y estudiosos de la antigüedad como ponen de relieve, además de las noticias periodísticas, los informes de las Actas de la Comisión de Monumentos de Oviedo (ADÁN ÁlVAREZ, 1997)

Las actuaciones que hemos desarrollado en Veranes sólo se comprenden en su justo alcance teniendo en cuenta las vicisitudes por las que han pasado estas ruinas desde su descubrimiento a principios de siglo hasta nuestros dias. Por esta razón, haremos un repaso de la historia de estas excavaciones, contemplando tanto los datos historiográficos como las acciones más recientes que han condicionado nuestro actual proceder.

No poseemos fuentes romanas que nos aporten información sobre el asentamiento de Veranes y la única referencia medieval es parca y oscura. Esta aparece recogida en el Liber Testamentorum, depositado en el archivo de la Catedral de Oviedo y creación del Obispo Don Pelayo en el primer cuarto del siglo XII. En el fol. 9 r. ${ }^{\circ}$, columna 2, líneas 15 y 16 se reproduce la donación otorgada en el testamento del Rey Ordoño I, fechado el 20 de abril del año 857, a la Iglesia de San Salvador de Oviedo de "in Veranes ecclesias Sancil Petri et Sanctae Marie de Riera et Sancte Eulalie de Cetnero". El hecho de que en la actualidad este pasaje se considere casi unánimemente como una falsificación pelagiana, nos obliga a contemplar el funcionamiento de la Iglesia de Veranes como cierto para el año 1100 , sin que podamos afirmar, a partir de la información textual, su existencia como lugar de culto con anterioridad.

Otro de los problemas de interpretación que genera tan brevisimo texto gira en torno a la advocación que poseeria esta iglesia de Veranes. En él aparecen recogidas lo que en apariencia son tres iglesias distintas localizadas en la actual parroquia de Cenero. La de Santa Eulalia no plantea más problemas al encontrarse enclavada, como el mismo documento nos informa, en el lugar de Cenero. Riera, por su parte, se encuentra colindante a Veranes y hasta el momento no existen indicios de que en este enclave se localizara una iglesia distinta a la del Torrexón de Veranes. Este hecho a llevado a que en la historiografia del yacimiento se halla planteado insistentemente una doble advocación, la de San Pedro y Santa Maria, para esta iglesia.

No contamos con otras fuentes escritas mas allá de este texto para acercarnos a la realidad histórica del yacimiento de Veranes. Este silencio de las fuentes textuales se corresponde también con un poderoso vacio historiográfico. La primera noticia que encontramos referida al Torrexón de San Pedro es recogida por Quadrado en 1855 en su obra Recuerdos y bellezas de España en el tomo dedicado a Asturias. En la pagina 175 podemos leer lo siguiente: "encima de la Venta de Veranes asoman ruinas de un edificio, que según indica su nombre, perteneció a los templarios". La referencia es vaga y la adscripción del topónimo de Veranes, o de la denominación popular de Torrexón. al mundo de los templarios confusa y difícil de trazar. En cualquier caso, la antigüedad del yacimiento se fija en la Edad Media y es una constante en la investigación posterior hasta entrada la década de los cincuenta del presente siglo. También introduce Quadrado la idea de que 
nos encontramos ante un complejo monástico, concepto que posteriormente volverá a aparecer para explicar la magnitud del yacimiento.

Pocas menciones más podemos encontrar en la historiografía asturiana sobre el ya* cimiento de Veranes a pesar de las dimensiones de la ruina, visibles desde la vía de comunicación más importante de Asturias, que une Oviedo con Gijón. Este silencio es difícil de explicar y probablemente tenga que ver con la consideración de los restos emergentes de Veranes como algo cercano en el tiempo, aún fuera de una dimensión histórica que justificara su estudio.

Podemos afirmar que hasta principios del siglo XX ningún autor aborda la tarea de realizar una investigación en profundidad. Será el cura párroco de la Abadía de Cenero, Manuel Valdés Gutiérrez, el encargado de revalorizar social y científicamente este yacimiento a partir de la década de los veinte del presente siglo. Con él se inician una serie de intervenciones que condicionarán las líneas maestras del proyecto que actualmente acometemos y que, por tanto, consideramos clave exponer como determinantes de nuestras actuaciones en la investigación en curso.

En el interés científico que el yacimiento de Veranes ha despertado a lo largo del siglo XX podemos trazar tres etapas bien definidas. La primera de ellas ocuparia la primera mitad de nuestro siglo y estaría marcada por los estudios emprendidos por Valdés. En 1918 publica su primer articulo en la prensa (VALDES GUTIÉRREZ, 1918) destinado a llamar la atención sobre la importancia y monumentalidad de las ruinas de Veranes. En este momento, se inician sus trabajos en el yacimiento (que tendrán su mayor auge en la década de los años veinte y treinta), y que le permitirán publicar en 1922 la obra titulada Iglesia y monasterio de Santa Maria de Veranes, en la que realiza una detallada descripción de la ruina y aporta las primeras propuestas interpretativas.

Por primera vez se relaciona la noticia referida a Veranes en el Liber Testamentorum con el Torrexón de San Pedro, aceptando la autenticidad del texto como testamento de Ordoño I, lo que permite a Valdés afirmar que a mediados del siglo IX existe ya la iglesia de Veranes con certeza. No analiza, sin embargo, la posible doble advocación asumiendo, sin argumentos que lo defiendan, el nombre de Santa María para esta iglesia.

Debemos detenernos en la designación que Valdés utiliza para referirse a las ruinas de Veranes ya que, al ser su obra de obligada referencia en los estudios posteriores, quedară fijada en la historiografía del yacimiento. Valdés hablará siempre de "Iglesia y monasterio de Santa María de Veranes". El mismo admite en su artículo de abril de 1918 la arbitrariedad de su decisión al referirse a la advocación de Santa Maria ${ }^{3}$ que le otorga a

3 "En primer hugar debo de advertir que la llamo iglesia de Santa Maria de Veranes y no de San Pedro. como el vulgo la llama "Torrexón de San Pedro" y como aparece frecuentemente en los escritos, porque la primer noticia que tuve de ella la llamaba asi, iglesia de Santa Marja. Yo por mi parte no pongo reparas a que se llame de San Pedro, pero yo por ahora continuaré llamándola iglesia de Santa Maria" Como vemos no justifica su decisión de acuerdo con ningún criterio científicamente valido, ni expone la fuente de la que toma tal designación. Lo cierto es que hasta el final de su vida continuará designando a los restos arqueológicos de Veranes asi lo que no serâ cuestionado hasta 1968 por Joaq̣uín Manzanares. Incluso después de esta fecha continúan apareciendo publicaciones que se refieren al Torzexón de esta manera (CORTNA FRADE. 1983). 
esta iglesia. No hace, sin embargo, ninguna aclaración sobre el motivo que le lleva a considerar las ruinas de Veranes como pertenecientes a un complejo monástico. Entregado a la causa de revalorizar y ensalzar los monumentos de su parroquia, Valdés se deja a menudo llevar por sus sentimientos", magnificando el papel de Cenero no solo en la historia de Gijón, sino en la de Asturias y en la propia historia de la "reconquista" Aquí encaja bien la interpretación de los restos de Veranes como propios de un gran monasterio, en funcionamiento ya en momentos muy tempranos de la cristiandad. Apoyando esta idea estarian la presencia de estructuras visibies anejas a la Iglesia y, tal vez, la lectura de obras anteriores con referencias al Torrexón como la citada de Quadrado. En la actualidad, en espera de que los resultados arqueológicos confirmen lo contrario, desestimamos la posibilidad de que podamos considerar validas las argumentaciones de Valdés en este sentido. Las estructuras adyacentes a la iglesia se interpretan como pertenecientes al complejo de la villa romana y carecemos de datos, por ahora, que nos permitan hablar de una reutilización en la Edad Media con carácter monástico.

Como aportación de Valdés, también debemos señalar el primer intento de realizar una adscripción cronológica de los restos arqueológicos de Veranes a partir del estudio interno de los mismos. De forma novedosa se señalan la presencia de elementos romanos en la obra del edificio, dato que permite al párroco determinar una antigüedad mayor de la esperada para la construcción de la iglesia. Conforme avancen sus estudios sobre Veranes, la cronología será retrasada cada vez más a la luz de la abundante presencia de elementos romanos. Si en su obra de 1922 defiende el siglo VI para la edificación de la Iglesia, en la década de los cincuenta hablará ya del siglo III, mostrando de esta manera la temprana y profunda cristianización de Asturias (y de esta forma también el carácter sobresaliente que en este proceso posee la zona de Cenero). En todo momento, como vemos, defenderá que las estructuras construidas en Veranes nacen ya con un carácter cultual cristiano, esto es, como Iglesia y monasterio desde el instante mismo de su edificación. Este planteamiento caracterizará, con alguna excepción (HuRlé, 1955), los planteamientos de los dos primeros momentos de la investigación que antes apuntábamos, siendo superados de forma definitiva en la década de los ochenta en la constatación del carácter de "villa" que en un primer momento tuvieron los restos arqueológicos de Veranes.

Si volvemos a ceñirnos exclusivamente al texto de 1922 existen otros datos, mas allá de los meramente historiográficos, de gran interés para el proyecto que acometemos. Estamos hablando de la descripción de los testimonios conservados a principios de siglo. El paulatino deterioro de la ruina (del que nos avisan tanto los escritos de Valdés como la documentación fotográfica) ha provocado que se pierdan de forma irreparable elementos arquitectónicos y decorativos de gran importancia para realizar una correcta in-

Téase, por ejemplo, El fuero o carta puebla de Gijón y el señorío de la Abadía de Cenero. Gijón, 1949 y Etapas notables de Ja fistoria de Gijón y su influencia en la Historia General de Asturias, Oviedo, 1952 obras en las que sitúa el centro neurálgico de la vida del concejo de Gljón en la Aita y Plena Edad Media en la Parroquia de Cenero. O El libro de oro de Covadonga Gijón. 1956 en el que otorga un papel destacado a los "monjes" de Veranes en la reorgantzación del ejército cristiano. 
terpretación del yacimiento arqueológico de Veranes. Así, Valdés describe los restos de decoración pictórica existentes en los ábsides del aula (hoy totalmente perdidos), la presencia de una puerta que comunicaria el aula con la sala octogonal (en la actualidad apenas insinuada), la fachada del aula (desplomada en 1934 a causa de su continuo uso como cantera). Y, también, nos alerta de las remociones de tierra, debidas a tareas agrícolas, en las inmediaciones de la ruina. Dicha información está apoyada, en parte, por las fotografías de la época que se conservan y que fueron publicadas por Manzanares en su obra de 1968.

Pero las investigaciones de Valdés en Veranes no se limitan a un estudio y documentacion de las estructuras emergentes sino que acomete la realización de "algunos sondeos en sitios diversos de este edificio" (VALDÉs GUTIÉRREZ, 1922:14). En estos momentos no podemos precisar con exactitud los lugares en que se llevaron a cabo dichos "sondeos", pero sabemos que se concentraron sobre todo en el aula y que sobre ellos incidirá más tarde la actuación de Joaquín Manzanares. Toda esta actividad determinará la ruptura de la extratigrafía en esta zona vital del yacimiento, problema que hemos tenido que asumir desplazando, así, esta clave interpretativa a alguna de las estancias anejas menos alteradas.

En los años treinta las investigaciones de Valdés supondrán una puesta en valor de la importancia histórica del yacimiento. La Comisión de Monumentos de Oviedo se interesará por los descubrimientos del párroco, y entre enero de 1934 y enero de 1936 el Torrexón de Veranes aparecerá tratado en las reuniones de la Comisión hasta ocho veces, en un intento por parte de ésta de asegurar su preservación y su estudio intensivo (ADÁN ALVAREZ, 1997). Reflejo de esta actividad es la aparición de artículos en la prensa local ${ }^{5}$ destinados a divulgar la importancia de los nuevos descubrimientos.

La actividad de Valdés en Veranes en las décadas siguientes debió disminuir notablemente si tenemos en cuenta la falta de publicaciones hasta los años los cincuenta. momento en que en el periódico El Comercio publica (VALDÉS GUTIERREZ, 1954) el hallazgo de un fragmento de mosaico, que segín el párroco confirmaría la cronología del s. III, fecha por él defendida en sus últimas propuestas, para la edificación de la iglesia.

Un ano más tarde Pedro Hurlé Manso, erudito local, vuelve sobre el tema, publicando varios artículos (HuRLE, 1955) y realizando una propuesta de reconstrucción para el mosaico, que estaría situado en la sala octogonal. Es importante senalar que en el artículo publicado en El Comercio el nueve de octubre de 1955 Hurlé defiende una interpretación novedosa sobre las ruinas de Veranes, señalando la obra original como romana y una posterior reutilización como iglesia. Incluso aina más su interpretación afirmando que nos encontramos ante "una vila romana de alguno de los jefes militares de la guarnición gijonesa". Si el intento de localizar la actividad del dominus de la villa es excesivamente arriesgado desde nuestra perspectiva actual, la exposición de la evolución de los restos arqueológicos que lleva a cabo suponen una ruptura con la historiografia precedente. Hurlé defenderá esta hipótesis en solitario, ya que no será retomada hasta la década de los ochenta.

5 "La Voz de Asturias", 19-i-1935. 2-4-1935. 14-4-1935 
En el periodo comprendido entre los sesenta y el inicio del Proyecto Gijón de Excavaciones Arqueológicas, en 1982, se sitúa un segundo momento en los estudios referidos al yacimiento de Veranes, caracterizado por la aparición de nuevos investigadores (rompiendo la tradición del "erudito local" que caracterizaba el primer periodo) que ofrecen una exposición mas ajustada de los restos y que pretenden ofrecer una interpretación fundamentada en el paralelismo, rompiendo de esta manera con el carácter excepcional y único que Valdés defendia para el Torrexón.

Gómez Moreno (GOMEZ MORENo, 1964), Joaquín Manzanares (MANZANARES, 1968) y Hauschild (HAUSCHIID, 1970) ${ }^{6}$ son los principales investigadores de esta etapa. Todos ellos van a señalar la vinculación existente entre Veranes y la Iglesia de Marialba (León), planteando, de este modo, una cronología visigótica para la edificación de la Iglesia de Veranes. Las propuestas de Hurlé de considerar el edificio como villa romana que posteriormente se reaprovecharía como lugar cultual, no serán siquiera consideradas en esta etapa, en la que se mantendrá un momento fundacional para el edificio religioso situado en torno al s. Vị- VII.

Será Manzanares el que intente realizar un estudio más profundo sobre el yacimiento, incluyendo nuevas intervenciones aleatorias en el aula y en las habitaciones adyacentes. En 1968 publica una síntesis de sus resultados dirigida a exponer la importancia y monumentalidad de la ruina en un intento de que le sea concedido el título de "Monumento Nacional" La propuesta será desestimada, pero Manzanares logrará atraer la atención institucional, consiguiendo que el Ayuntamiento de Gijón adquiera los terrenos en los que se localiza el yacimiento. En el mismo año de 1968 se produce la compra, lo que de alguna manera aseguraba la protección de los restos ${ }^{7}$ y facilitaba la labor de investigación.

Manzanares realiza una nueva lectura de la documentación existente, revisando las conclusiones a las que llegara Valdés. Asume la interpolación del Obispo Don Pelayo en la información referida a Veranes y plantea un nuevo análisis del texto, llegando a la conclusión de la doble advocación de la iglesia, que sería denominada de "San Pedro y Santa Maria de Riera". Pondrá un acento especial en el estudio de lo que él interpreta como baptisterio ${ }^{8}$ y que justifica su análisis de la Iglesia de Veranes como sede episcopal de Lucus Asturum de acuerdo a una lectura errónea y forzada del Cronicón de Idacio. También realizará un estudio de la ruina, planteando una hipotética reconstrucción ${ }^{9}$, de acuerdo a paralelos con la Basílica de Santa Inés en Roma, que se fundamenta en una imagen prefijada de lo que debería de ser una iglesia paleocristiana, en la que se intenta

${ }^{6}$ En el que adscribe la iglesia de Veranes al grupo portugués de Sintra y Falperra (Braga).

${ }^{7}$ Esta afirmación es más que matizable ya que no fue acompañada de una labor de cercado que asegurara la preservación del yacimiento. Esta importante tarea no ha sido acometida hasta el inicio del presente proyecto.

${ }^{B}$ Que coincide con la habitación octogonal que hoy identificamos claramente como sala calefactada perteneciente a la villa. Esto anula cualquier hipótesis que utilice como elemento expositivo su carácter sacro original

${ }^{9}$ Dificil de aceptar en la actualidad de acuerdo a la interpretación vigente de la gran sala como aula de la villa. 
encajar los restos de Veranes. Para reforzar su hipótesis, y ante la falta de elementos materiales que lo confirmen en el propio yacimiento, plantea la presencia de restos arquitectónico decorativos reutilizados en la iconostasis de Santa Cristina de Lena y en la Cripta de Santa Leocadia de Oviedo, que originariamente estarian enclavados en la Iglesia de Veranes. Esta argumentación es somera y carece del rigor necesario para plantear si quiera un debate científico.

El tercer momento de la investigación se inicia en la década de los ochenta y aparece caracterizado por la interpretación de los restos arqueológicos de Veranes como pertenecientes a una villa romana. La importancia de la fase romana de Veranes fue puesta de relieve por uno de nosotros en 1982 (FERNÁNDEZ OCHOA, 1982 y 1993) y entonces atribuimos al yacimiento una cronología entre fines del siglo I d.C. o inicios del II d.C.y el siglo IV d.C. sobre la base del análisis de los restos de las pinturas murales, los mosaicos y los materiales diseminados por el pórtico de la Abadía de Cenero, todos ellos fruto de la recogida incontrolada llevada a cabo entre los años cuarenta y cincuenta. En las mismas fechas, M. Fernández-Miranda se hacia eco de todas las propuestas anteriores incidiendo en el carácter basilical del conjunto y en los numerosos problemas interpretativos aún pendientes (FERNÁNDEZ MIRANDA, 1983)

Las investigaciones sobre Veranes iniciaron una nueva y ültima etapa a partir de 1982, momento en que se puso en marcha el llamado "Proyecto Gijón de Excavaciones Arqueológicas" propiciado por el Ayuntamiento, el Ministerio de Cuitura y la Consejeria de Cultura del Principado de Asturias. Bajo la dirección de L. Olmo se realizaron cuatro campañas de excavaciones entre 1983 y 1987 que, por razones diversas, no tuvieron continuidad si bien aportaron, en publicaciones de carácter general, algunos datos renovadores sobre la interpretación y la cronología del yacimiento (OLMO ENCISO, 1984; OLMO ENCISO y VIGIL ESCALERA, 1992 y 1995)

El yacimiento de Veranes ha sido definido como una importante villa tardortomana, ocupada ya desde el Alto Imperio y con una dilatada prolongación durante el periodo medieval (Lám. I). Las excavaciones de L. Olmo se centraron principalmente en dos terrazas. La meridional corresponde a la zona del "Torrexón" (o el aula) y las construcciones anejas al mismo que se interpretan como la pars urbana de una gran villa tardía con sus termas, mientras que en la terraza Norte se han documentado una serie de estancias con materiales que, según este autor, inducen a pensar en un área de ocupación altoimperial convertida, durante la tardía romanidad y los primeros siglos altomedievales, en un espacio para desarrollar actividades metalúrgicas.

Esta interpretación, aceptable en términos generales, dista mucho de ser definitiva mientras no se continuen las excavaciones, dado que no ha sido posible atribuir una correcta funcionalidad a los distintos ambientes excavados. El espacio considerado tradicionalmente como basilica paleocristiana o visigoda, sería para L. Olmo, una gran sala absidiada de un complejo termal o como parte de la construcción señorial de una villa romana. Las sucesivas estancias calefactadas y frias de la parte occidental podrian corresponder a unos balnea, pero para determinar su plan de circulación y su funcionalidad exacta se requiere un estudio profundo de la técnica edilicia y de las soluciones tectónicas y aéreas empleadas en su construcción. 
En cuanto a la terraza superior situada al Norte, se han localizado restos de habitaciones todavía mal conocidas para el período de uso romano, pero que han ofrecido restos interesantes de actividades metalúrgicas. En concreto, se halló un horno de forma oval con paredes de piedra caliza unidas con un mortero muy arenoso; en sus entornos se recogieron restos de escorias y carbones. En otra habitación se descubrió un enlosado de calizas y un depósito de agua de planta circular que se ha interpretado como una posible forja ${ }^{10}$. El desarrollo de estas actividades relacionables con la metalurgia del hierro, se sitúa a partir del abandono de los balnea en el curso de los siglos v y vi d.C. La materia prima debía proceder de la zona próxima conocida como Pozu la Mina. Es probable que la explotación continuase en la Edad Media. Nos hallamos a la espera de que se publiquen las excavaciones por L. Olmo hasta 1987.

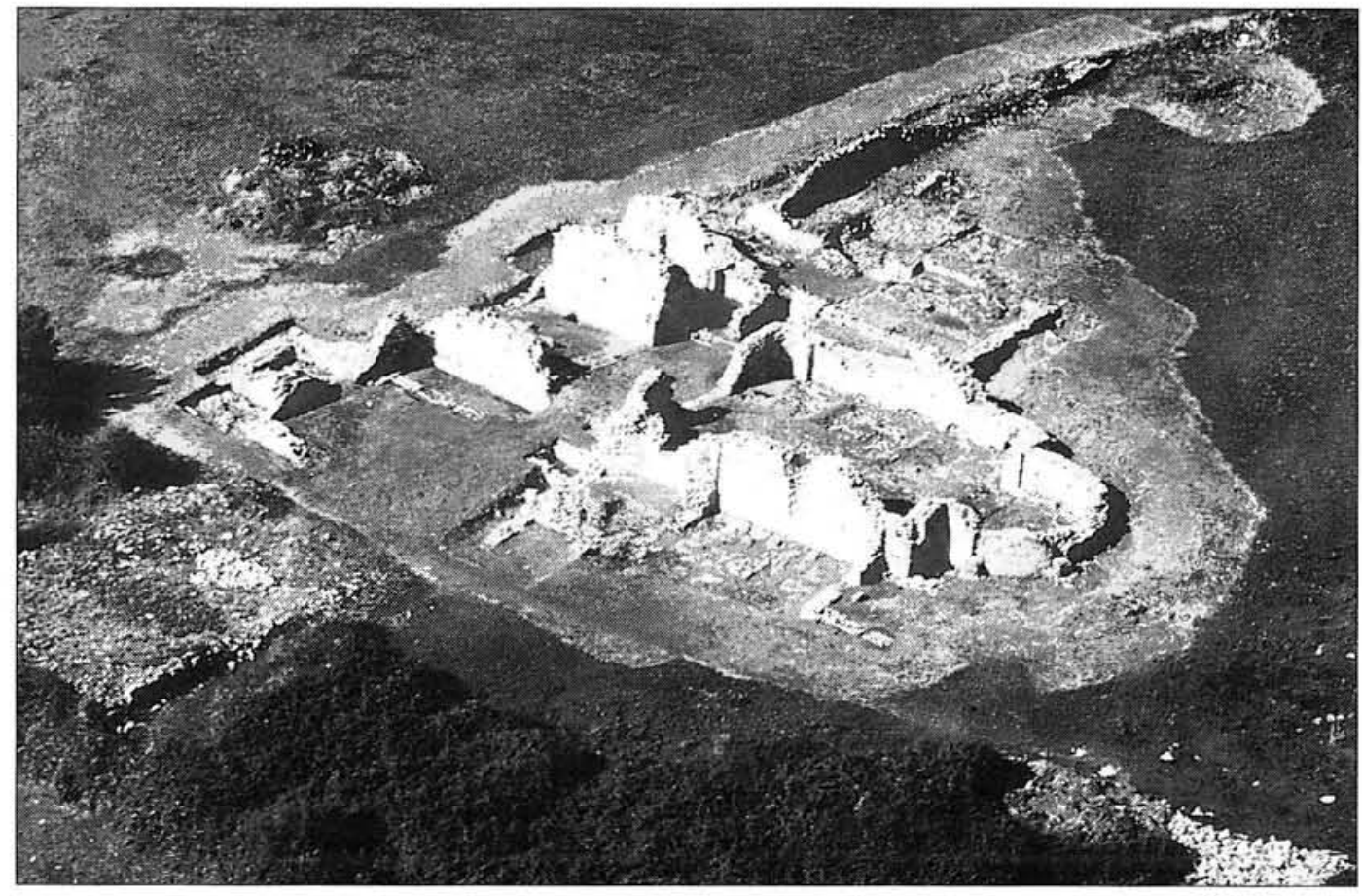

Lämina I.-Vista general del área de las excavaciones antiguas al finalizar las lalores de limpieza (Campañà (le 1997)

En una fecha imprecisa, la gran Aula absidiada se transformó en iglesia en cuyos entornos surgirá una necrópolis de tumbas de lajas que al asentarse rompen parte de las construcciones romanas precedentes. No ha sido posible precisar la cronología de estos enterramientos que quizá cluraron varios siglos. La iglesia, como ya se ha dicho, aparece

${ }^{10} \mathrm{No}$ se han publicado ni fotos ni planta de estas estructuras, tan sólo contamos con una breve des-

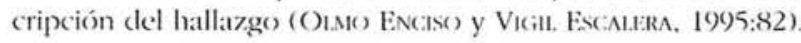


citada en el Liber Tastamentorum (siglo XII) en la donación de Ordoño I a la iglesia de San Salvador de Oviedo fechable a mediados del siglo IX. Si bien es cierto que el documento pertenece a la interpolación pelagiana del siglo XIl, se admite su validez como referencia de antigüedad fijada en la memoria histórica del momento.

A partir de 1988 se detuvieron los trabajos de investigación en Veranes. La Consejería de Cultura del Principado solicitó a la dirección científica la presentación de una Memoria acerca de los trabajos realizados en años anteriores y la propuesta de un proyecto de consolidación, con el fin de proceder a la conservación y tratamiento de las estructuras exhumadas que se hallaban sometidas a un deterioro cada vez mayor. Al parecer no se llevó a cabo la ejecución de este compromiso y los trabajos quedaron temporalmente interrumpidos.

Uno de los obstáculos para realizar las excavaciones y para poner en valor este yacimiento, era la dificultad de conocer las dimensiones exactas de las fincas propiedad del Ayuntamiento así como la determinación de los accesos a las mismas. En la actuaildad, una parte de las actuaciones de nuestro proyecto se ha dirigido precisamente a buscar soluciones para resolver los muchos problemas de infraestructuras aún pendientes.

\section{PROYECTO DE ACTUACIÓN EN EL YACIMENTO DE VERANES}

\section{Objetivos del proyecto}

Dentro de esta segunda etapa del Proyecto Gijón de Excavaciones Arqueológicas. el yacimiento de Veranes ocupa un lugar preferente tanto por la categoría y evidencia de los restos arqueológicos emergentes cuanto por su ubicación en el área suburbana de la ciudad romana de Gijón. Todos los investigadores interesados por el problema de la transición del mundo romano al medieval. consideran a Veranes como uno de los lugares paradigmáticos en donde se podría obtener información de primera mano sobre esta cuestión primordial en el contexto de la historia del Principado. En consecuencia, retomar las tareas de excavación y consolidación del yacimiento entraba dentro de la lógica de las actuaciones promovidas y financiadas por el Ayuntamiento de Gijón en los últimos años ${ }^{11}$ con el fin de recuperar los datos pertinentes sobre el origen y la evolución histórica de Gijón y su Concejo.

Como objetivos concretos nos propusimos:

- Documentar las estructuras emergentes mediante el empleo de innovadores criterios topográficos, informáticos y fotogramétricos.

- Consolidar y recuperar los restos ya exhumados.

"Queremos expresar nuestra gratitud al Ilmo. Ayuntamiento de Gijon en la persona de su aicalde. Vicente Álvarez Areces, por confiarnos, una vez más, la puesta en marcha de un nuevo proyecto arquueológico en el concejo gijonés. 
- Recuperar los mosaicos y pinturas aún in situ.

- Excavar de forma sistemática la necrópolis medieval, con análisis antropológico de las inhumaciones.

- Rematar la excavación del supuesto conjunto termal y restituir, con valor didáctico, alguno de los elementos que lo conforman.

- Planificar nuevas excavaciones en los espacios intactos del yacimiento.

- Delimitar la extensión del yacimiento.

- Documentar una secuencia estratigráfica precisa.

- Elaborar un estudio histórico-arqueológico de los resultados completado con la realización de análisis de arqueofauna, polen, arqueometalurgia así como de las producciones cerámicas etc. con el fin de obtener una secuencia histórica justificada del área rural de Gijón en época romana.

Igualmente nos propusimos promover las actuaciones en infraestructuras para la protección y puesta en valor del yacimiento:

- Adquirir las fincas que configuran el entorno de la Ería del Torrexón de Veranes y que permiten la delimitación del conjunto arqueológico mediante linderos naturales.

- Vallar las fincas que son propiedad del Ayuntamiento.

- Preparar los accesos al yacimiento.

- Incoar la Declaración de BIC (Bien de Interés Cultural).

- Coordinar las acciones correspondientes a fin de preparar el yacimiento para su presentación pública dentro de la ruta arqueológica del Concejo (Restos romanos del centro histórico (Cimadevilla), castro prerromano y romano de Campa Torres, villa romana de Murias de Beloño, Torre-palacio de los Valdés, Fortaleza medieval de Peñaferruz etc.).

\section{Trabajos realizados en 1997}

\section{A. Avance en la dotación de infraestructuras}

Las actuaciones desarrolladas en 1997 se centraron en la limpieza, documentación y consolidación de las estructuras emergentes, acciones previas indispensables a la hora de acometer un nuevo proyecto de investigación en el yacimiento. Asimismo, el Ayuntamiento de Gijón ha ido dotando al yacimiento de Veranes de una serie de infraestructuras necesarias para el desarrollo en los próximos años del proyecto de investigación y adecuación para su exposición pública. Estas infraestructuras consistieron en la creación 
de un acceso permanente a las fincas donde se ubica el asentamiento por medio de un camino de zahorra, el valiado progresivo del yacimiento con malla metálica, con el cierre del acceso asi como la instalación de las acometidas de agua y electricidad en la finca municipal donde se localiza la ruina.

\section{B. Propuesta para la documentación de las estructuras}

En colaboración con el profesorado de la Escuela Universitaria de Ingeniería Técnica Minera y Topográfica del Campus de Mieres (Universidad de Oviedo), se decidió elaborar un método de registro Topo-Cartográfico del ámbito de intervención del emplazamiento romano-medieval de Veranes capaz de conjugar los recientes avances tecnológicos de las técricas de medición y almacenamiento de información con los de la investigación arqueológica.

El modelo establecido, una vez concluido, deberá servir como eficaz herramienta en el procesamiento y gestión de los datos y puesta en valor del monumento. Este modelo creemos que puede constituirse en una eficaz guía de actuación para cualquier intervención de caracteristicas similares en el Patrimonio Histórico.

\section{B.1. DESCRIPCION GENERAL DEL PROCESO}

El proceso consiste esencialmente en la realización de un Levantamiento Topográfico del entorno próximo al enclave que permite su adecuada Geo-referenciación (ubicación espacial coordenada), de tal manera que la posición absoluta de cualquier objeto (posición sobre la superficie terrestre entendida como totalidad) pueda documentarse en $\mathrm{X}, \mathrm{Y}$ y $Z$ con un error inferior a los $20 \mathrm{~cm}$. y de modo relativo (los objetos o elementos constructivos entre si) de unos $5 \mathrm{~cm}$. Este espacio que supera los $5.000 \mathrm{~m}^{2}$, se localiza y desarrolla en coordenadas geográficas (longitud y latitud) y en el sistema cartográfico oficial ${ }^{12}$. La toma de datos de campo se realiza mediante procedimientos de distanciometria infrarroja y observación angular con estaciones totales computerizadas en un primer momento y se comprueba después mediante técnicas de posicionamiento global por satélite (G.P.S). Durante esta fase se ha establecido una Red de Referencias Topográficas señalizada mediante mojones prefabricados tipo Feno y clavos galvanizados de adecuada permanencia que enlaza varias zonas de interés arqueológico dentro del concejo gijonés y en el entorno de la antigua vía romana que comunicaba la Meseta con la ciudad romana de Gijón.

${ }^{12}$ Que en virtud de la Ley de Ordenación de la Cartografia en Esparia de 1.968 es la Proyección Uninversal Transversal de Mercator estando las coordenadas $\mathrm{X}$ e $\mathrm{Y}$ referidas al huso $\mathrm{N}$. ${ }^{\circ} 30$ y las altitudes al nivel medio del mar en Alicante (datum altimétrico). 
Apoyándose en la Red de Bases implantada, se ha elaborado un modelo tridimensional detallado del contorno de las ruinas emergentes cuyos paramentos verticales, de hasta $3,5 \mathrm{~m}$, se extienden por una ladera en pendiente orientada al Sur sobre una superficie de unos $1500 \mathrm{~m}^{2}$ Esta operación se ha lievado a cabo utilizando miniprismas ópticos de reflexión y dianas reflectantes y se complementa, en cuanto a la documentación de los paramentos, con un novedoso procedimiento de rectificación digital de fotografias.

Se desarrolla un método de registro y almacenamiento de los datos que permite su posterior manipulación, exportación y gestión con programas informáticos diversos a fin de elaborar presentaciones en dos y tres dimensiones de imágenes reales, virtuales e híbridas encaminadas a la divulgación del monumento.

\section{B.2. CARTOGRAFIA NUMÉRICA ARQUeOLOGGICA}

Toma de datos

Tanto el levantamiento topográfico de los puntos singulares del yacimiento como el de las parcelas colindantes y la transferencia de los mismos al software de dibujo se ha realizado a través de procesos digitales automatizados (por medio de estaciones totales, colectores de datos y receptores G.P.S.) que han permitido la localización exacta del yacimiento y su almacenamiento en soporte magnético minimizando los errores debidos al operador.

Los aparatos de campo utilizados para estas fases han sido: Teodolito T-2 de 1cc. de apreciación angular, Estación Total TC-500 de $10 \mathrm{cc}$. de apreciación angular y precisión en distancia de $2 \mathrm{~mm}$. +/- 2 ppm., y receptores G.P.S monofrecuencia S.R. 9.400 , todos ellos de la casa LEICA. Como colector de datos un PSION ORGANIZER con conexión RS-232.

Volcado y tratamiento de los datos

Una vez capturados los datos, éstos se vuelcan en programas topomáticos de cálculo (TOPCAL, GALITOP 4.2, CARTOMAP.4) que permiten su ajuste y compensación exportando la posición de los mismos en el sistema coordenado predefinido (U T.M.) al software de dibujo (AUTOCAD v.14 y MICROSTATION SE en este caso). A partir de estas posiciones espaciales de los puntos notables de la ruina, se elaboran modelos digitales tridimensionales (de contornos, de curvas, triangulares o de malla cuadrada) con los que obtendremos la representación del relieve adecuada para cada caso concreto (utilizamos en este caso CARTOMAP Y TERRAMODELER como programas de modelización 3D). Simultáneamente los datos se convierten a 2D para su tratamiento en planta mediante el sistema de representación convencional de planos acotados.

Ya en AUTOCAD o en MICROSTATION y tras un previo diseño de simbología, se dibujan las estructuras y codifican los datos (limites de estancias, cabeceros de muros, 
pavimentos, sebes, curvas de nivel, etc.) organizándolos en niveles de información jerarquizados y diferenciados mediante color, capa, tipo de línea y peso.

El formato de intercambio de datos grá́icos escogido es el .DXF y el .DWG v.12 de AUTODESK que mediante los oportunos diccionarios de transferencia ofrece en el momento presente las menores pérdidas de información y posibilita la exportación hacia COREL DRAW, entorno MACINTOSH, 3D ESTUDIO etc. (debe tenerse en este caso un especial cuidado con el tratamiento y compatibilidad de polilíneas, lineas Bézier, spilineas o curvas matemáticas diferentes de la circunferencia y con el uso de fuentes y estilos de texto diferentes).

Toda la información se gestiona una vez codificada según su tipología. Tanto en AUTOCAD como en MICROSTATION el programa permite la incorporación de nueva información que se importa (en los formatos antes citados: DXF o DWG v 12) al tiempo que se va desarrollando la investigación (nuevos componentes estructurales, unidades estratigráficas, elementos muebles significativos).

Sobre los datos gráficos compilados se realizan operaciones topológicas en 2D (proximidad, pertenencia, adyacencia etc.) mediante aplicaciones S.I.G. integradas con el C.A.D. Estos softwares son respectivamente MAP en el entorno AUTOCAD y GEOGRAPHICS en el de MICROSTATION. Paralelamente se trabaja en la creación de Bases de Datos relacionales que se vincularán a los ficheros gráficos una vez completadas las fases de excavación y clasificación.

Interacción con el dibujo de campo

Una vez obtenida la planta del yacimiento con las lineas de los muros que definen las estructuras, se imprimió una copia a escala 1:40 que sirviendo como canevás o minuta de campo permite en el terreno incorporar las piedras y elementos constructivos que definen cada estancia. A continuación, el plano completado en campo se escanea (a 1 bit y $300 \mathrm{ppp}$ de resolución en formato BMP) y se vectoriza manualmente en pantalla utilizando el bitmap como fichero de referencia.

Estas operaciones se realizan en COREL DRAW v.8. y en el momento presente estamos estudiando la posibilidad de automatización parcial y total del proceso mediante los siguientes procedimientos:

- Vectorización automática de los dibujos escalados de plantas y alzados tomados en campo mediante seguimiento de trazos por línea centrada o por contorno.

- Dibujo digital en campo sobre el fichero minuta mediante libretas digitales.

Justificación del software utilizado

El motivo de haber elegido este software no esencialmente cartográfico es múltiple: por una parte propicia una excelente convivencia de formatos raster y vectorial. Dispone 
además de buenas herramientas para el tratamiento de texturas, tramados, etc., permitiendo tanto la obtención de magníficas salidas de color a través de periféricos de trazado (plotters de chorro de tinta, láser o sublimación) como la creación de planchas separadas de cuatricromía para la inclusión en publicaciones de forma inmediata. Igualmente facilita la realización de presentaciones multimedia, animaciones etc. a través por ejemplo de COREL PRESENTS V.2 o de otros programas similares.

\section{B.3. OBTENCION DE FOTOPLANOS DIGITALES}

El modelo de documentación por fotografía rectificada se desarrolla como un procedimiento alternativo a la fotogrametría terrestre convencional con el fin de saivar los inconvenientes que ésta conlleva: dificultades de las tomas ante limitación del espacio disponible, multiplicidad de las mismas, necesidad de levantar andamiajes para abordar elementos con gran desarrollo vertical, complejidad y elevados costes del proceso etc. Se puede realizar segun una de estas cuatro propuestas: APROXIMADO, ANALOGICO o EMPÍRICO, SEMI-NUMÉRICO y NUMÉRICO (SUAREZ, ET ALII 1998).

El método practicado en Veranes desarrolla un procedimiento para la obtención de fotoplanos digitales muy simplificado que no requiere necesariamente personal especializado y que posibilita su realización sin incurrir en graves deformaciones con cámaras convencionales de calidad (esencialmente de paso universal, $35 \mathrm{~mm}$. o de formato medio como el $6 \times 6$ ) y el material de laboratorio de un aficionado. Corresponde al proceso denominado ANALOGICO o EMPÍRICO.

El paramento es fotografiado con una cámara reflex de focal comprendida entre los 28 y $80 \mathrm{~mm}$. procurando que la toma sea lo más perpendicular posible respecto al plano que se quiere representar (en todo caso se recomiendan inclinaciones menores de $\left.20 .^{\circ}\right)$. Las velocidades de obturación serán como mínimo de $1 / 60$ segundos si la toma se realiza sin tripode y con el diafragma lo más cerrado posible (f 11-22) de modo que utilicemos solamente la parte central del objetivo ya que es ésta la que ofrece menores distorsiones métricas.

El muro o fachada a documentar, asimilado a un plano, es referido con dos plomadas y un cerco metálico cuadrangular de dimensiones conocidas que permitirá después en el laboratorio orientar la rectificación de la imagen y su escalado aproximado. Simultáneamente, se situan dianas en puntos singulares y extremos de la toma que definirán las verdaderas dimensiones del muro. La distancia entre las mismas se puede obtener simplemente midiéndola con cinta métrica $o$, si se quiere, se pueden determinar sus coordenadas con una estación total y un miniprisma.

Ya en el laboratorio, la imagen se rectifica en una ampliadora sobre un bastidor o meseta milimetrada diseñada por el equipo de la E.T.I. Topográfica de Mieres que permite corregir el error de la inclinación de la cámara con respecto al objeto fotografiado y la reconstrucción de la posición relativa de los pianos perspectivos (muro o fachada y 
plano focal en el momento de la toma) que constituyen una homografía afectada de diversos errores instrumentales.

Una vez positivadas las imágenes rectificadas, éstas son escaneadas convirtiéndose en bitmaps. La fotografia se retoca (contraste, saturación, exceso de iluminación) en un programa de tratamiento de imagen (COREL PHOTOPAINT). A continuación, en COREL DRAW se escala la imagen comparando alguna de las distancias medidas en el campo y se van dibujando las piedras (vectorización manual) que definen el paramento (Lám II).

El método permite capturar la información en el campo por medios fotográficos y topográficos a un coste económico y en muy poco tiempo, posibilita la representación de paramentos verticales de tamaños pequeños y medios de forma sencilla, sin andamiajes ni estructuras complementarias y genera unos ficheros digitales manipulables con interesantes posibilidades tanto para su análisis como para la propuesta de hipótesis de reconstrucción y su divulgación.

El equipo utilizado tras la realización de las pruebas correspondientes consistió en: Cámara Nikon F-601. Objetivo Nikkor: 28-80. Ampliadora Durst M-370 con cabezal de color, Películas Kodak Tri-x 400 (pancromática convencional) y TMAX-400 (grano T), y Papel Ilford multigrado deluxe brillo.

\section{Consolidación de las estructuras}

Una vez realizado el registro de las estructuras conservadas se procedió a la consolidación de muros, pavimentos, pinturas y enlucidos con el fin de evitar su progresivo deterioro. Los trabajos de restauración consistieron en el reforzamiento de los cabeceros de los muros mediante su recrecido mínimo con hiladas similares a la edilicia de las estructuras interponiendo un estrato de intervención de láminas de pizarra y caucho de butilo entre el original y el añadido. Se limpiaron las llagas de las juntas reforzándose aquellas que presentaban un mayor deterioro. Los escasos restos de pinturas murales y enlucidos conservados en los paramentos se limpiaron y consolidaron, las lagunas fueron rellenadas y los bordes rematados con mortero. Los pavimentos hidráulicos, presentes en varias estancias, se limpiaron y sus bordes se restauraron cubriéndose a continuación dichas superficies con sacos de tela sintética transpirable rellenos de cerámica expandida. Además, se realizó al arranque de un fragmento de mosaico localizado durante las excavaciones de L. Olmo. Los restos del pavimento musivario fueron consolidados y dotados de nuevo soporte y se encuentran actualmente en estudio.

\section{Campaña arqueológica de 1998}

En 1998 se inició la fase de excavación arqueológica del yacimiento. Como actuación previa se consideró conveniente la evacuación de las antiguas terreras localizadas 


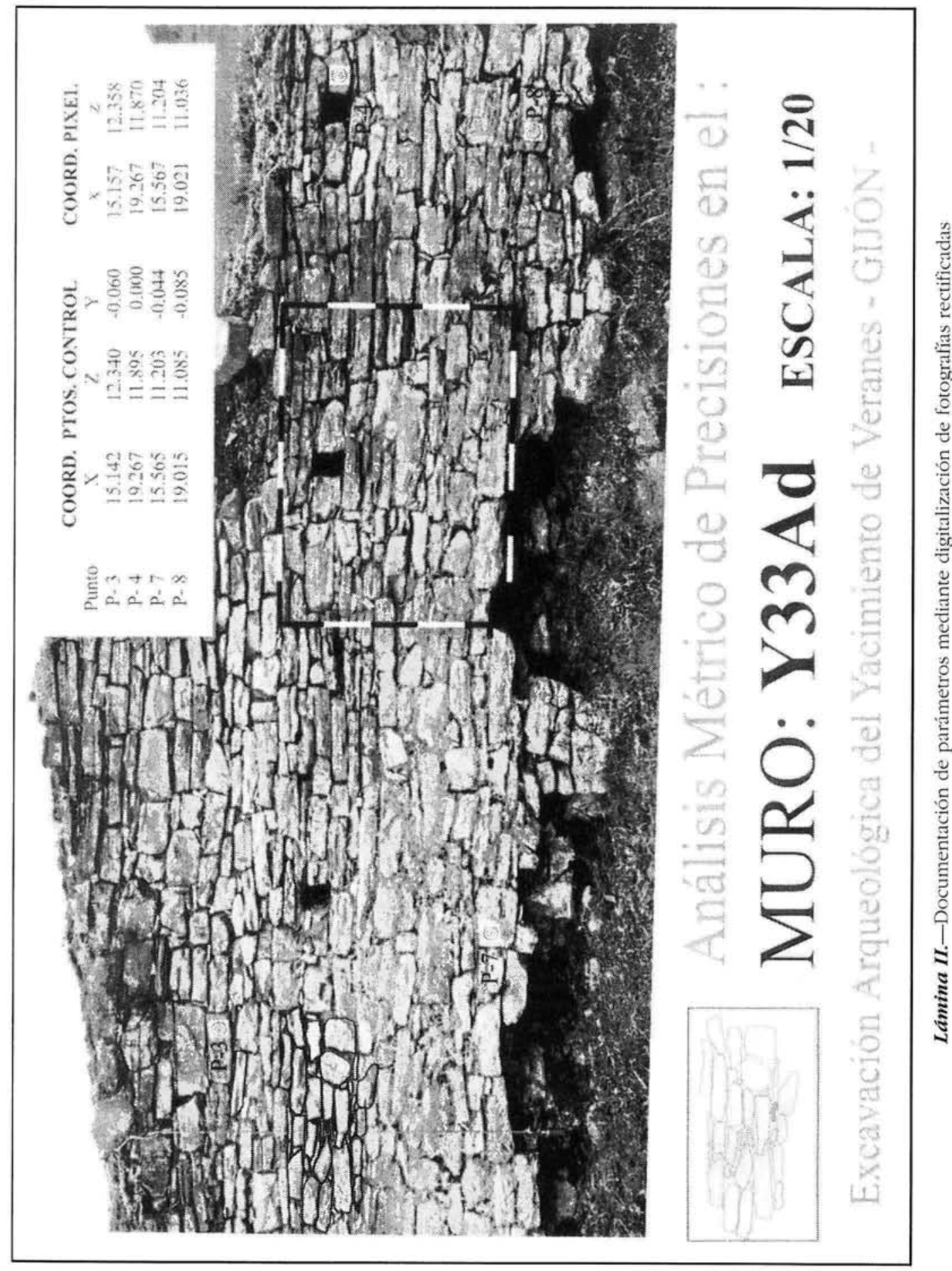


al sur del monumento y la planificación de un vuelo sobre el yacimiento y las fincas colindantes para obtener un reportaje de fotografía por infrarrojos en blanco y negro y color que permitiera identificar bajo tierra algunos elementos que ayudasen a delimitar la extensión de las estructuras. Así mismo está previsto que se aplique posteriormente este método al estudio de los paramentos con el fin de reconocer reparaciones y fases constructivas encubiertas en los diferentes muros.

Una vez realizados estos trabajos, se ha desarrollado la campaña de 1998 que en la actualidad se centra en la zona oeste y norte del yacimiento y en los puntos sin terminar de excavar existentes dentro de las estancias conocidas ${ }^{13}$

Los presupuestos metodológicos que se aplicaron en la intervención arqueológica suponen una continuidad de las directrices iniciadas en la campaña de 1997 completados con el desarrollo de un método integral de registro arqueológico para la documentación de las diferentes fases históricas del yacimiento basado en la exhumación de los estratos por unidades arqueológicas (UU.EE.) y su registro informático espacial.

La red de cuadrículas se ha levantado a partir de un eje de coordenadas localizado en el extremo suroccidental de las fincas municipales. Los cortes mantienen unas dimensiones de $6 \mathrm{~m}$ este-oeste por $4 \mathrm{~m}$ norte-sur sin testigos, orientados adaptándose a las estructuras emergentes y a las catas identificadas de las excavaciones precedentes. Así, el norte arqueológico se define ligeramente desviado hacia el oeste del norte geográfico real. Las dimensiones de los cortes permiten, además, su protección con módulos de invernadero si la situación meteorológica lo requiriera.

La numeración de las catas se basa en el eje de coordenadas siguiendo los métodos de identificación topográficos. Así, la cuadricula es nombrada según su ubicación con respecto ai 0-0 del eje, indicando su posición por columna $(\mathrm{X})$ y fila $(\mathrm{Y})$. Este método permite la numeración objetiva de los cortes y la identificación espacial rápida de las cuadrículas (Fig. 2).

El registro arqueológico se ha realizado teniendo en cuenta las deposiciones naturales y antrópicas adaptándose el método a las necesidades del yacimiento. Las unidades arqueológicas identificadas se documentan en fichas diseñadas especificamente para una base de datos relacional que permite gestionar toda la información recuperada y combinar tanto aspectos estadísticos, cronológicos, típológicos como gráficos y los elementos muebles significativos son topografiados para su correcta ubicación espacial en el estrato.

El método de documentación de las estructuras presenta algunos problemas de registro ya que la ruina emergente conservada carece de asociación estratigráfica y nos obliga a tratar su documentación de forma independiente a los estratos. Los muros se han identificado según su posición y orientación en el eje de coordenadas general ( $\mathrm{Xn}$ para los orientados norte sur. Yn para los orientados E-O y Tn para los muros tangen" ciales) y se han descrito siguiendo unas fichas-tipo de documentación edilicia. En el pro-

${ }^{13}$ La actuación en estos espacios se ha basado en la posibilidad de recuperar el registro arqueológico y documentar las inhumaciones existentes. 
ceso de excavación, la integración de estas estructuras en una matriz general se propone manteniendo su denominación y conservando el método de registro de muros en el proceso de documentación de las excavaciones futuras, recogiendo la relación del muro con los estratos asociados en las fichas estratigráficas de edilicia.

La actuación arqueológica, todavía en curso, se ha centrado en cuatro áreas del asentamiento (Fig. 2):

- Area norte: se realizaron dos sondeos con el fín comprobar la extensión del yacimiento en este sector. El corte 584/494 resultó estéril en estructuras documentándose exclusivamente, en un único estrato, material cerámico medieval y moderno procedente de arrastres. En el sondeo 536/564 se ha documentado la continuidad de las estructuras romanas que definen una posible cuarta terraza del edificio. Dichas estructuras configuran dos estancias ligeramente escalonadas y pavimentadas con mosaicos polícromos de tipo geométrico y la presencia de enterramientos de época medieval.

- Área oeste: Se han abierto tres zonas siendo sus resultados provisionales desiguales. El corte $476 / 544$ no proporciono, al igual que el $584 / 494$, evidencias arqueológicas. Las zonas excavadas determinadas por las ordenadas 532 y 516 constatan la continuidad de las estructuras que definen el emplazamiento rural en este sector. Se han documentado hasta el momento en esta zona varias estancias con pavimentos de opus signinum y un sistema de escaleras de sillares de arenisca. También se registra un suelo exterior de guijarros con materiales cerámicos tardorromanos (T.S.H.T., cerámica común). Sobre la ruina y amortización de las estructuras se documenta una necrópolis alto y pleno medieval de lajas. Algunas de sus tumbas conservan la señalización exterior, consistente en una laja caliza sin trabajar hincada en el cabecero de la inhumación. Así mismo, se registra en este sector los restos de un suelo de uso medieval asociado a los enterramientos. El material cerámico recuperado en este espacio se compone fundamentalmente de fragmentos de piezas globulares con decoración incisa de ondas, reticula y peinadas alto y pleno medievales.

- Área de las excavaciones antiguas: Se han retomado las antiguas excavaciones en la estancia situada al este de la piscina (sondeos 536/512, 536/508, 536/ $504,542 / 512,542 / 508,542 / 504)$, en donde se documentan una serie de muros paralelos orientados este-oeste cuya función todavia no está totalmente clarificada pero que podrian actuar como subestructuras para igualar el nivel del aterrazamiento o como refuerzo de las cimentaciones en la fachada sur del edificio. Entre estos muros se ha documentado unos depósitos de escombros y elementos constructivos de época romana entre los que destacan varios fragmentos de mosalco similares a los documentados in situ en el yacimiento.

Finalmente, en esta misma zona pero en el área noreste del edificio (sondeos $548 / 532,554 / 532$ ) se ha localizado una estancia calentada por un horno 


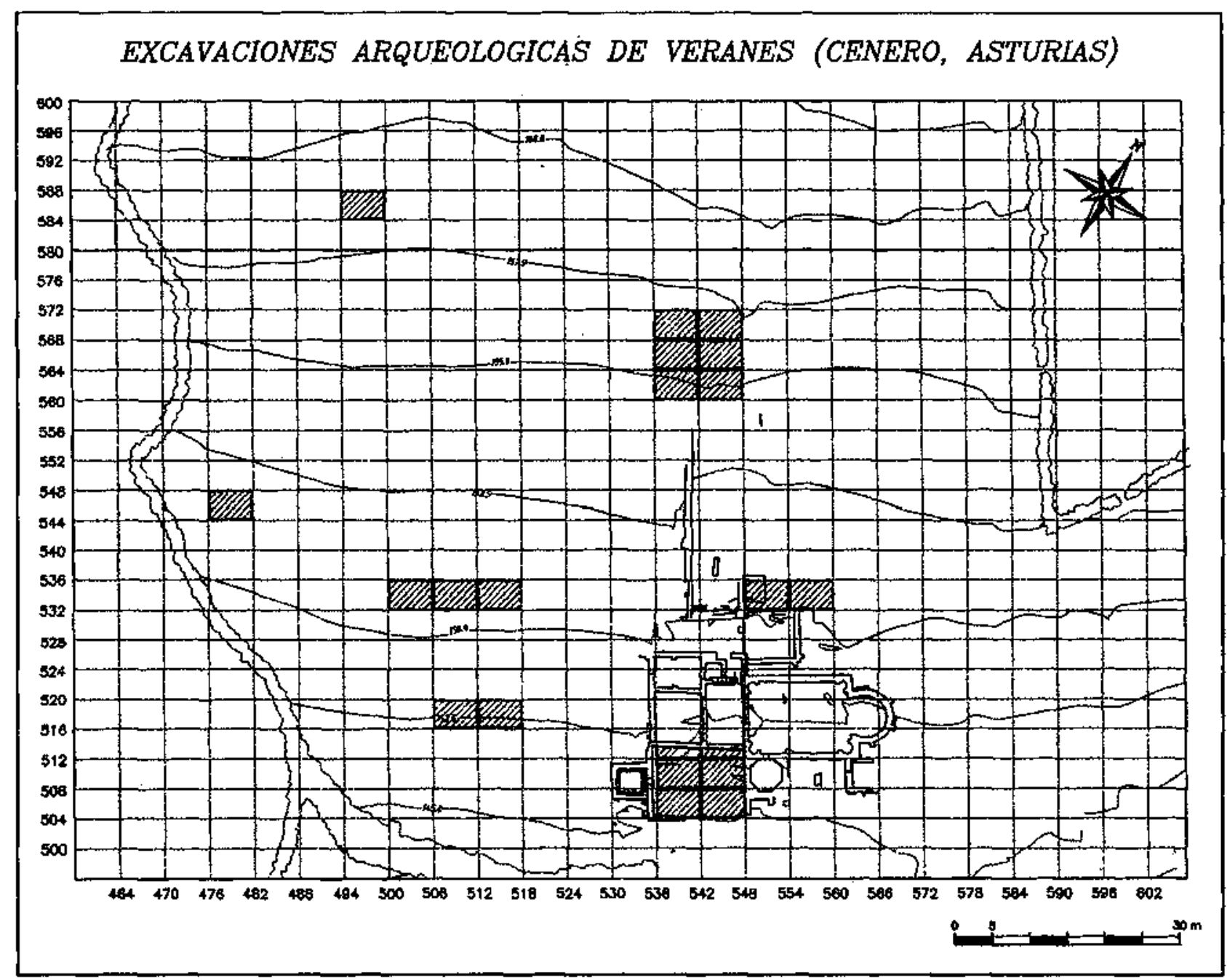


situado en la fachada este y los restos de un suelo exterior de guijarros utilizado en el siglo IV d.C. (Lám III). Esta habitación se encuentra junto al espacio que L. Olmo interpretó como zona de forja y en la actualidad se halla en proceso de excavación.

\section{CONSIDERACIONES HISTÓRICO-ARQUEOLOGICAS}

Los resultados provisionales de esta primera campaña de excavaciones permiten plantear algunas cuestiones del máximo interés a la hora de avanzar en el conocimiento del importante enclave tardio que fue Veranes.

Las características de los paramentos y la composición de los muros de las nuevas estancias descubiertas, tanto en el área norte como en la parte occidental así como su orientación, no ofrecen dudas acerca de su pertenencia al mismo complejo que el Aula y sus estructuras adyacentes conocidas ya desde antiguo. Hemos podido determinar, en consecuencia, que el desarrollo del yacimiento viene a ocupar un espacio aproximado $1 \mathrm{Ha}$. Esta cifra otorga a Veranes una mayor importancia en comparación con los restantes conjuntos rurales asturromanos y permite relacionar su extensión con establecimientos tardoantiguos de otros ambitos rurales hispanos florecientes entre los siglos IV y $\mathrm{V}$ d.C. y más en concreto, con núcleos de la Meseta norte.

En cuanto a la cronologia, no nos ha sido posible constatar, de momento, una fase Altoimperial como sugerian Olmo y Vigil (Olmo y VIGIL-ESCALERA, 1995:228). En el intento de corroborar este dato, se abrió el sondeo 554/532, al lado del trazado por nuestros predecesores. Se localizó un nuevo praefurnium ${ }^{14}$ (Lám. III) pero la secuencia estratigráfica asociada a los muros donde se ubica este nuevo hogar, apunta a una fecha claramente tardía. Otro tanto sucedió en los cortes del área occidental determinados por las ordenadas $532 / 518$ que mostraban una sucesión de estancias cuadrangulares una de las cuales presentaba restos de escalones y otra un pasillo y la base de una escalera. Un antoniniano de fines del siglo III d.C. y los fragmentos de T.S.H.T. del primer estilo asociados a estas estructuras, auguran también fechas bajoimperiales en este sector. Por tanto, en ningún caso ha sido posible retrasar la cronologia que arroja una fecha de construcción del conjunto hacia la primera mitad del siglo IV d.C., fecha que podría ser matizada en campañas posteriores. Como ya apuntaran Olmo y Vigil-Escalera, aparecen algunos materiales altoimperiales en posición secundaria pero no sólo en esta zona sino en los rellenos de casi todo el yacimiento sin que de momento sea posible relacionarlos con estructuras romanas anteriores.

${ }^{14}$ A propósito del hallazgo de esta nueva estancia calefactada, anotamos nuestras dudas acerca de la conformación del espacio termal al sudoeste de las ruinas tal y como suponian Olmo y Vigil-Escalera. La sucesión de estancias dista bastante de ser canónica, además de no incorporar al circuito la habitación octogonal también calefactada. Estimamos que debe ser revisada esta interpretación, máxime cuando en una zona alejada de los supuestos bartos, hallarnos otro preafurnio de factura muy similar al documentado en el área de excavaciones antiguas. Esperamos que las investigaciones futuras nos permitan esclarecer estas dudas. 
Acerca de la transformación para uso metalúrgico de ciertas áreas del yacimiento durante el período bajoimperial avanzado (siglos v-VI d.C.) tal y como proponían Olmo y Vigil-Escalera poco se ha podido aclarar hasta la fecha. La zona donde estos investigadores supuestamente localizaron una fragua, se encuentra en un lamentable estado y únicamente la publicación de ese sondeo podrá esclarecer este supuesto. Los restos de escorias se clispersan por todo el yacimiento pero aún no hemos clocumentado estructuras asociadas a estas actividades ni materiales específicos de esa cronología. En efecto, a diferencia de lo que sucedía en el casco antiguo de Gijón donde localizamos series de materiales importados o de producción local-regional (incisas, impresas o las que hemos denominado "cerámicas de acabado vesicular") datadas entre finales del siglo v y el siglo Vi d.C. (FlrnńNi)lz OCHOA, et alii, 1992), en Veranes no se han hallado todavía piezas de importación atribuibles a este horizonte.

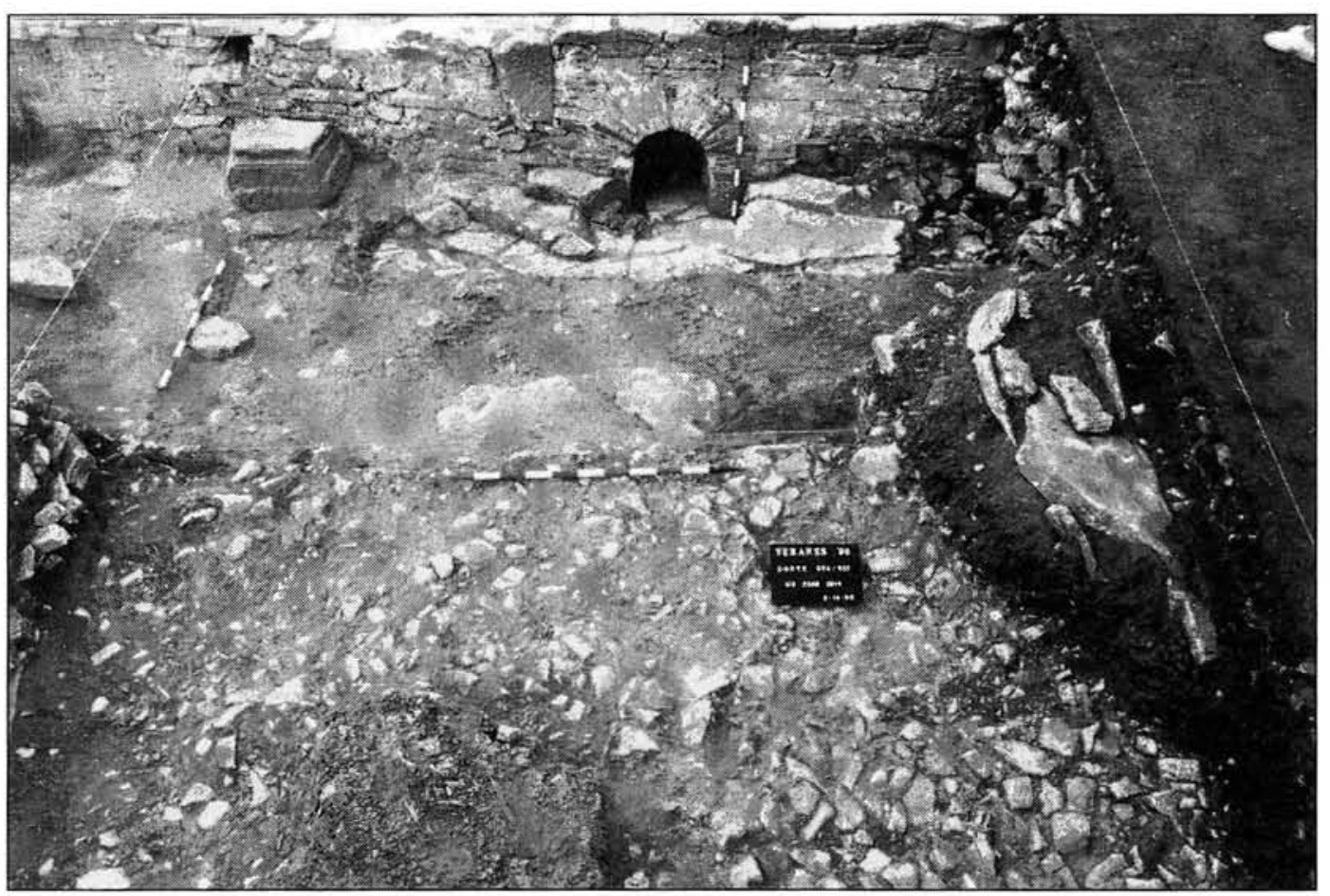

Lámina III.-Nuevo praefurnium del área situada al nordeste del Aula

En cuanto a la fase medieval, por lo que hemos podido comprobar en nuestros sondeos, no nos es posible establecer de momento una sucesión de etapas tan concreta como la establecicla por Olmo y Vigil-Escalera.

Las intervenciones asignables a una fase medieval, comprendida posiblemente entre los siglos Ix y el xII, son la utilización del Aula como iglesia bajo la advocación de Santa 
Maria y San Pedro, el uso de las estancias situadas al oeste del Aula como zona de servicio de la iglesia (habitaciones consideradas por Olmo y Vigil-Escalera como la parte termal de la villa romana) y la construcción de un muro en "L" que oblitera parcialmente el gran pasillo central del edificio y que se relaciona estrechamente con uno de los espacios de servicio.

El resto de lo que fuera el establecimiento romano se utilizó como cementerio con enterramientos en lajas, algunos con material latericio reutilizado. Como suele ser habitual, las tumbas se asientan sobre los pavimentos o rompen los muros romanos adecuándose a la orientación preestablecida. Se ha excavado en esta campaña un total de 50 tumbas, la mayoría con individuos completos y sin ajuar. Interesa resaltar la localización de varias tumbas señalizadas mediante una laja vertical, dato de gran interés que no siempre se puede documentar. Lamentablemente estas rudimentarias estelas no presentan ni textos ni decoración alguna. Los materiales asociados a los suelos de uso o a las fosas realizadas para proceder a la deposición, se componen de clavos, hierros informes y, sobre todo, cerámicas de tono gris-azulado con decoración ondulada en el cuello así como ollas, jarras, cuencos y cazuelas con decoración incisa vertical u horizontal o bien formando entramados de cuadros. A pesar de la extrema fragmentariedad de las piezas, se pueden reconocer los tipos comunes a todo el horizonte alto y plenomedieval asturiano.

Por último, la campaña de 1998 nos ha permitido comprobar la estructuración del yacimiento de Veranes que se levantó en terrazas atendiendo a la topografia del terreno. Los muros se apoyan generaimente sobre la roca basal, sin zarpas ni rellenos de acondicionamiento previo. En la terraza superior se ha documentado la excavación previa de la roca para cimentar la estructura.

De sur a norte, se encuentran las tres terrazas inferiores donde se ubica el Aula y las estancias adyacentes al norte y al oeste. Nuestros sondeos han evidenciado la ocupación de otra terraza superior quedando estructurado todo el espacio en cuatro terrazas $^{15}$. En la situada más al norte hemos hallado dos estancias con pavimentos musivos policromos que presentan decoración geométrica y una factura muy similar a los fragmentos recuperados en el Aula ${ }^{16}$.

\section{PROTECCIÓN Y ADECUACIÓN DEL YACIMIENTO PARA EL DISFRUTE CIUDADANO}

Al Ánalizar la campaña arqueológica se han sellado los cortes con tela sintética transpirable (geotextil) y gravilla de construcción. Así mismo, los pavimentos se han protegido con el geotextil, gravilla y cerámica expandida (arlita) al $50 \%$ con el fin de aliviar el peso de la capa de protección.

${ }^{15}$ La diferencia de cota entre la terraza tercera y cuarta resulta tal vez demasiado grande por lo que cabe pensar que existiera una terraza intermedia en cuyo caso el yacimiento se habría levantado en cinco terrazas. Este dato se podrá confirmar en excavaciones sucesivas.

${ }^{16}$ Todos los restos de mosaicos recuperados en intervenciones antiguas y rellenos asi como los pavimentos musivos hallados in situ están siendo objeto de un estudio específico 
Durante esta campaña se ha avanzado en la protección del enclave, subsanándose en gran medida, con la construcción del cercado metálico, el problema del acceso incontrolado a la ruina. Asi mismo, dicha actuación ha eliminado el riesgo de la entrada de ganado en el yacimiento.

En cuanto al futuro del yacimiento, es intención del Ilmo. Ayuntamiento de Gijón integrar la villa ${ }^{17}$ de Veranes en la ruta arqueológica del Concejo. Por esta razón, teniendo en cuenta la importancia de las ruinas conservadas y su interés histórico, se ha encargado un proyecto de adecuación de todo el espacio que sea compatible con la continuidad de los trabajos arqueológicos. Se trataría de una primera actuación consistente en facilitar, en determinadas épocas del año, visitas guiadas a las ruinas mediante la instalación de un sistema de pasarelas móviles con puntos de información y de la creación de espacios ajardinados en el entorno. Dicha actuación estará acompañada de las obras correspondientes para cercar definitivamente el yacimiento y realizar los drenajes. Al finalizar las excavaciones actualmente en curso, se procederá a la musealización del conjunto.

\section{BIBLIOGRAFIA}

ADÁN ÁLVAREZ, G. (1997) "Intervenciones arqueológicas de la Comisión de Monumentos Históricos Artísticos de Oviedo (1844-1978)" Lancia 2, Salamanca.

CORTinA FRADE, I. (1983): "La Abadia de Cenero en los tiempos antiguos", Portfolio de las Fiestas de Cenero, Gijón.

Diego SANTOS, F. (1978): Historia de Asturias. Asturias romana y visigoda, Salinas.

FERNÁNDEZ MIRANDA, M. (1983): "Gijón en época romana", Indigenismo y romanización en el Conventus Asturum, Madrid.

FERNÁNDEZ OCHOA, C. (1982): Asturias en la época romana, Madrid.

- (1993) "Mosaicos de Asturias", Mosaicos romanos de León y Asturias, Corpus de Mosaico de España, fasciculo X, Madrid.

- (1995) "Astures y Roma. la configuración del territorio", Astures. Pueblos y culturas en la frontera del Imperio Romano, Gijón.

- (1996): "Historia del Proyecto Gijon de Arqueologia", Homenaje a Manuel Fernández Miranda, Complutum Extra 6 (I), Madrid.

FERNANDEZ OCHOA, C., et alii (1992) " "Gijón en el período tardoantiguo: cerámicas importadas de las excavaciones de Cimadevilla", Aespa 65, Madrid.

GOMEZ MORENO, M. (1964): "Primicias del arte cristiano español", Archivo Español de Arte 154-155. Madrid.

\footnotetext{
${ }^{17}$ Mantenemos de momento el término "villa" aplicado a este yacimiento sin menoscabo de que en un futuro se puedan matizar o concretar esta denominación.
} 
HAUSCHILD, T. (1970): "Die Martyrer-Kirche von Marialba bei León" Legio VII Gemina. León.

HuRLE, P. (1955): "El mosaico romano de Veranes", El Comercio, Gijón, 9 de octubre de 1955 y 18 de diciembre de 1955.

MANZANARES, J. (1968). El Torrexón de San Pedro, en Veranes, basilica paleocristiana con baptisterio (VII) entre Oviedo y Gijón. Oviedo.

OLMO ENCISO, L (1984) "Excavaciones arqueológicas en Veranes", Gijón Romano, Gijón.

OLMO ENCISO, L., y VIGIL ESCALERA, A. (1992): "La villa romana y medieval del Torrexón de Veranes", Los origenes de Gijón, Gijón.

- (1995): "Veranes, un espacio histórico de época romana y medieval", Astures. Pueblos y culturas en la frontera del Imperio Romano, Gijón.

QUADRADO (1855): Recuerdos y bellezas de España, Madrid.

SUÁREZ. J A.; GONZALEZZ-PUMARIEGA, P.; VIDAL, A., y ARGUUELLES, R. (1998) "Levantamiento de fachadas, techos y suelos mediante digitalización de fotografias convencionales rectificadas" X Congreso Internacional de Ingeniería Gráfica, Máiaga.

VAlDÉs GuTIÉRREZ, M. (1918). "Iglesia de Santa Maria de Veranes", La Prensa, Gijón.

- (1922) Iglesia y monasterio de Santa María de Veranes, La Felguera.

- (1949) El Fuero y la Carta Puebla de Gijón y el señorio de la Abadia de Cenero, La Felguera.

- (1952) Etapas notables de la Historia de Gijón y su influencia en la Historia General de Asturias, Oviedo.

- (1954) "El mosaico de Veranes", El Comercio. Gijon 20 de octubre de 1954.

- (1956): El hibro de oro de Covadonga, Gijón. 